\title{
Ghanaian Local Aluminum Cast Utensil Forms for Fountain Production
}

\author{
${ }^{1}$ Benjamine Ansah , ${ }^{2}$ Kafui Kwesi Agyeman (PhD), ${ }^{3}$ Harold Awuley Quaye and ${ }^{4}$ Frederick Ampah Clement \\ 1, 2, 3, 4 Department of Integrated Rural Art and Industry, Faculty of Art, \\ Kwame Nkrumah University of Science and Technology, Kumasi, Ghana
}

\begin{abstract}
In Ghana, movable fountain production has not been industry friendly especially to our local material producing industries in Ghana. Materials like Resin, silicon and fine marble stone which are not traditionally produced materials in Ghana are what most fountains used in Ghana are made of. This has made fountain production and repairs very difficult and expensive. The local material producing industries equally produce strong and good materials and forms that can be effectively employed in fountain production. Applying and repairing fountains produced in these local materials and forms are less costly and easier. For this reason, this study focuses on the forms of locally cast aluminium utensils for the production of fountains. In spite using these utensils for cooking purposes, it was also observed that, they have form that elated to some elemental forms in the production movable fountains. This study aimed at identifying the forms of the Ghanaian aluminum cast utensils suitable for the different parts of a movable water fountain. In this regard, data was collected through observation and interviews of selected stakeholders of the foundries in Tamale and Kumasi which formed the population for the study. In relation to existing fountains the forms were subjected to conceptual analyses which resulted in three concepts. these concepts were further subjected to matrix evaluation based on affordability, attractiveness, sustainability, strength, functionability, lightness of weight, and size. This arrived at a more efficient design. This was further subject to fabrication experimentations in line with the design. The result of this study is a locally cast aluminum utensil water fountain. it is called 'water fall and cascading' fountain based on the design and water flow. The study has proven that the forms and functions of these utensils make an ideal fountain that is ecofriendly, safe, less costly and easy to maintain. The study recommends further research into how to adopt the holistic output of foundry items of the local industry for both demand driven and thought-provoking fountains and other design forms.
\end{abstract}

Keywords:- Fountains, Ghanaian aluminium cast utensils, Design, Local materials, Sustainability.

\section{INTRODUCTION}

The aluminum utensils in Ghana are purposely produced for cooking and they range from the pot to the pounding mortars. These utensils are made such that they can contain substances, example water or heavy food stuff per the forms they come in. These forms can be seen as conical, half round or spherical. These utensils as the name goes are casted from raw aluminum cans and aluminum ingots according to Yusif, (2015) and (Hannah, 2015). The forms the utensils present inspired Dr. Kafui Kwesi Agyeman: a lecturer in the Metal section of the Department of integrated Rural Art and Industry of the Kwame Nkrumah University of Science and Technology- Kumasi to introduce a course content that challenged students to picking up forms from the locally cast aluminum utensils market and developing art pieces from them. This was the foundations of the water fountain concept employing the local utensils.

Fountains create beautiful splash effects we behold most times or give laminar flow (Cotton, 2004). Fountains have got a function and this function can only be achieved with the help of the various parts and how they also function. There are the distributors, concealers, collectors and reservoir DUSE (2017), (Jessica Kolifrath, n.d.). And all these come together to make up a fountain. Besides Water fountains come in different forms according to Beyond the Veranda, (2014) and these are indoor, out door and under the each are different types. These utensils on the other hand have forms that relates to the mentioned functions very well.

In the light of this, the local aluminum utensil casting industry has been observed to have great potentials for fountain production. This study therefore subjects selected cast aluminum utensils to fountain oriented analysis towards a future of fountain making. This is expected to benefit the benefit to founders of the utensils and artisans as stated under the sustainable development goal eight: "decent work and Economic growth". This is perceived in this respect through the alternative use of the utensils is by fountain producers who will employ the utensils when producing fountains generally.

It's evident from literature that the forms of the utensils can be of great benefit to both fountain production and the founders of the utensils. 


\section{METHODOLOGY}

The qualitative method was used to unearth opinions and thoughts for the designs. The study employed the qualitative method to explore the utensils and how best it can be employed in fountain production. Observations and interviews were conducted to attain the right and detailed data from the right sources. Descriptively, the study related the aluminum cast utensils to fountain production by outlining the various forms and functions as well as the various types of water fountains that can be possible. This design was also used to illustrate some sketches that transcended into the prosed concept created during the study. Action research was employed to strategize the utensil for utilization in fountain production. before the above research designs, a survey was conducted to identify the forms and functions of the utensils regarding their applicability. This survey was conducted in in Kumasi and Tamale, fountain producers in Kumasi and Accra, because they bear similar characteristics. This population was able to purposively sample out the utensils that are good enough and suitable for indoor fountain production.

The survey identified most of the Ghanaian Aluminum Cast Utensils on the market and from analysis eight different utensils were chosen based on their functional properties as shown in Figures 1 to 8:

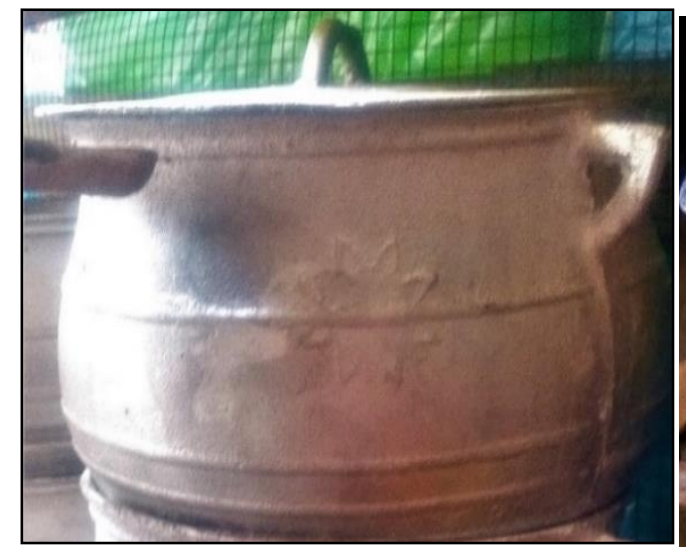

Fig 1:- A view of the metal pot.

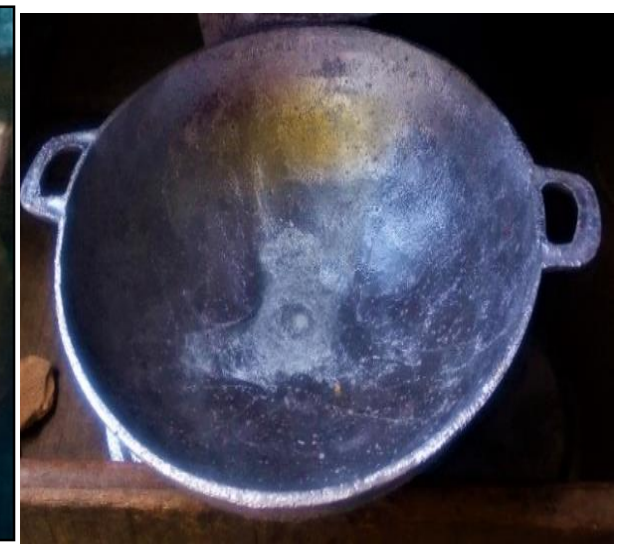

Fig 2:- The aluminum pan.

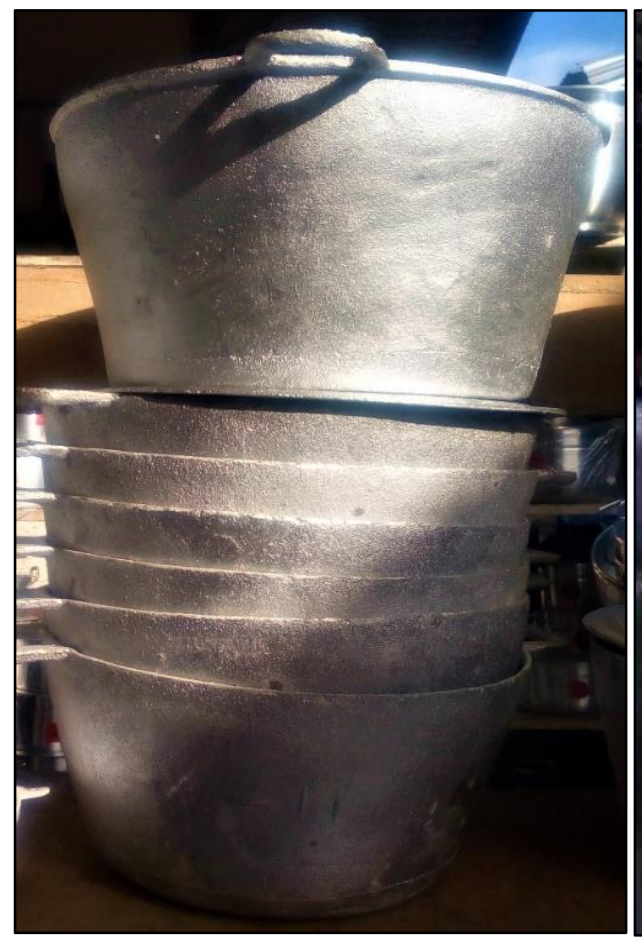

Fig 3:- The Storing bowl.

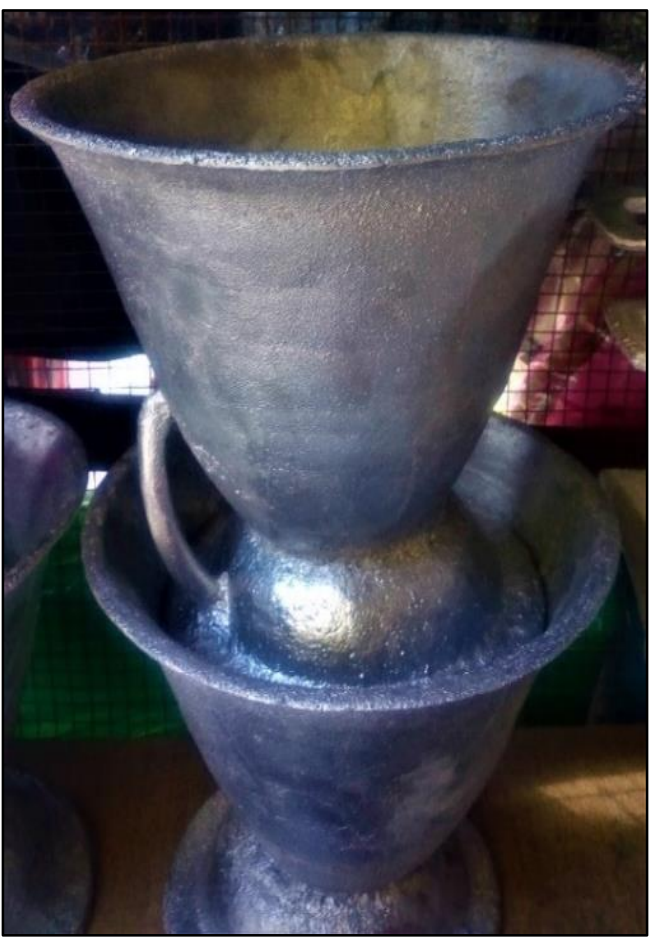

Fig 4:- The metal pounder. 


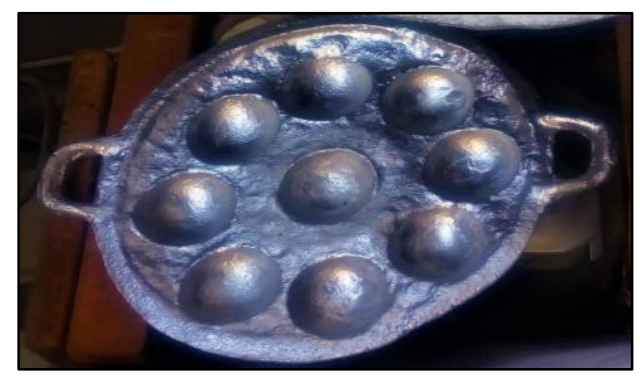

Fig 5:- The Baker or frier.

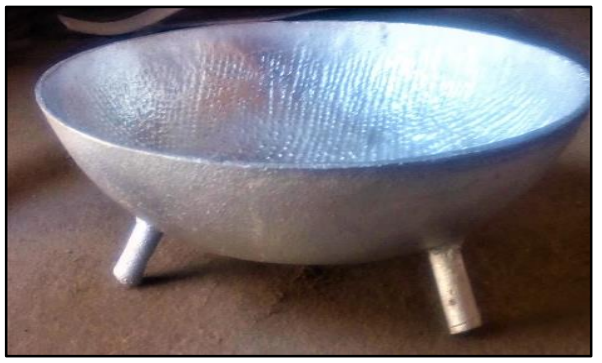

Fig 6:- The Grinder.

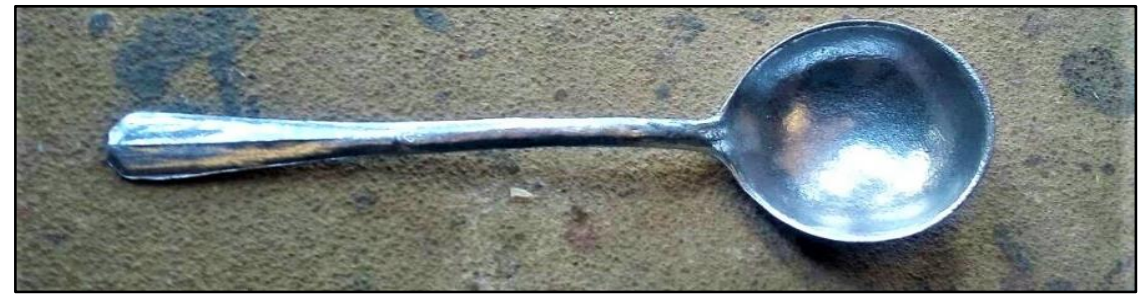

Fig 7:- The ladle

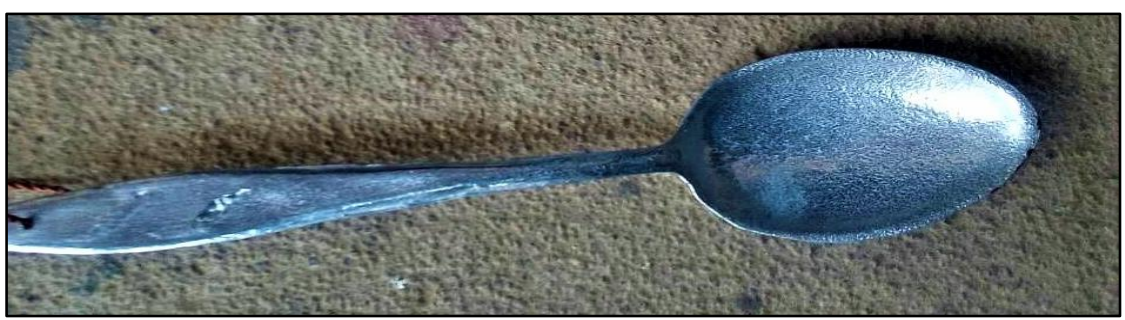

Fig 8:- The Spoon.

From the data collected the study shows that with aluminum cast utensils, there are many utensil types, choice and form that can suit any form of cooking. Ganiho (2017). From the above pictures some analysis was made with reference to the four parts that makes up a fountain: the basin, distributer, concealer/stand and collector. The illustration below shows how each of the constant parts can be represented by the utensils listed above.
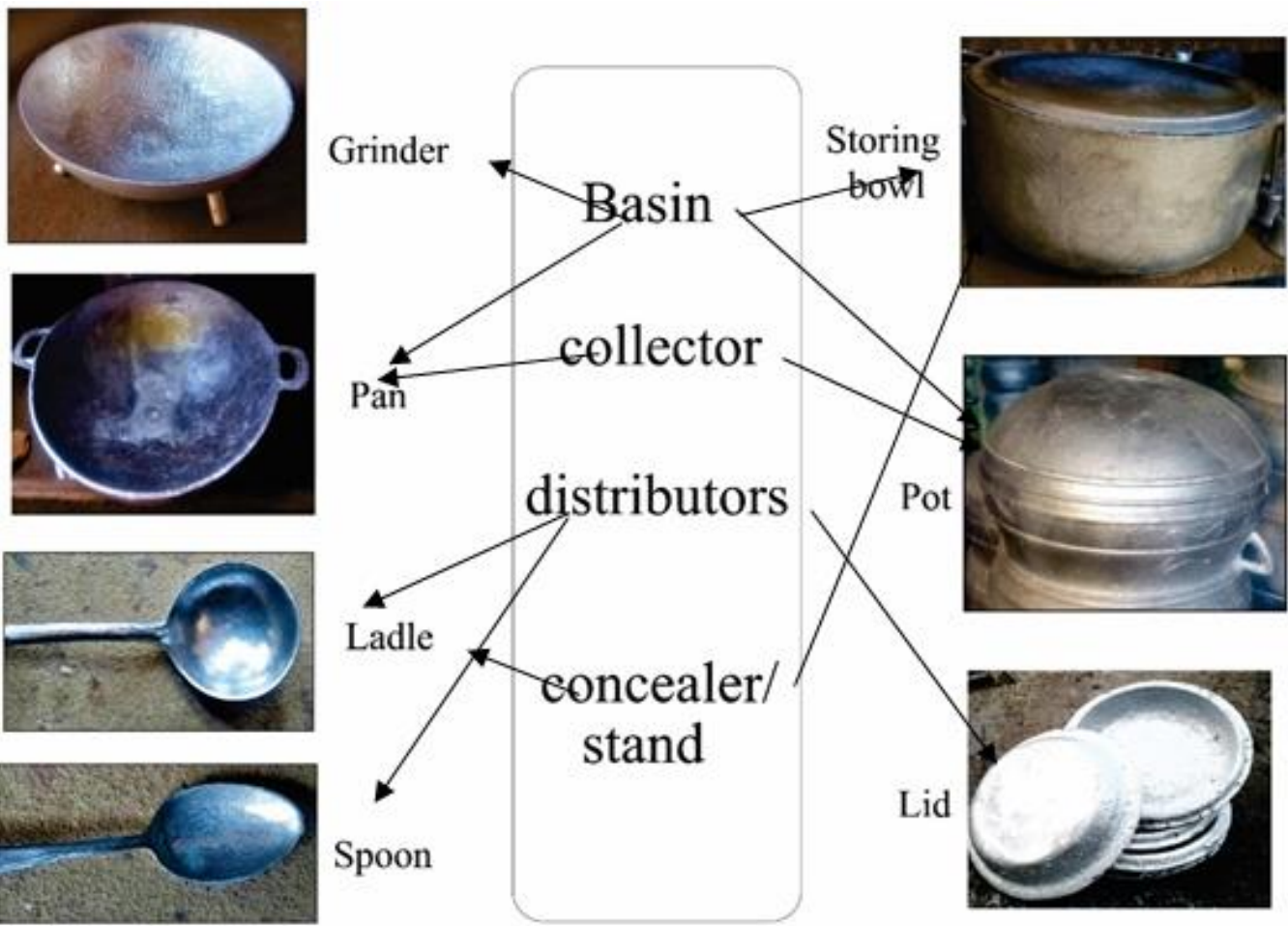

Fig 9:- An illustration showing how the utensils can be present in the four constant. 


\section{The Design Process}

Based on the forms selected, the design process ensued with series of sketches of fountain concepts that are in relation to their functions as shown in Figures 10 and 11 base on the defined element in figure 12. After brainstorming, different ideas were put on paper and their breakdown in terms of the forms and functions of the utensils. Furthermore the sketches were shortlisted according to their looks and simplicity.

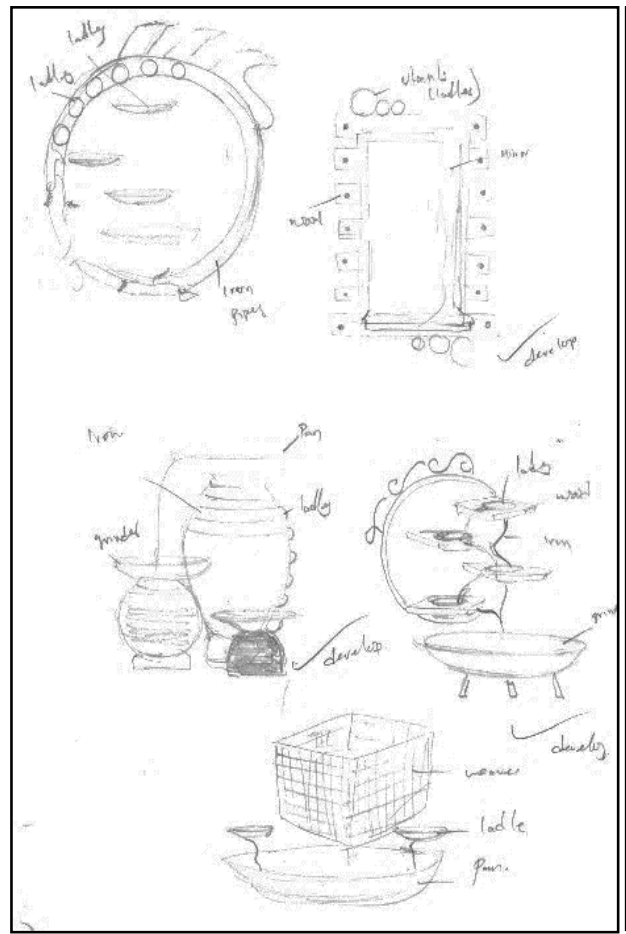

Fig 10:- Skeches of concepts

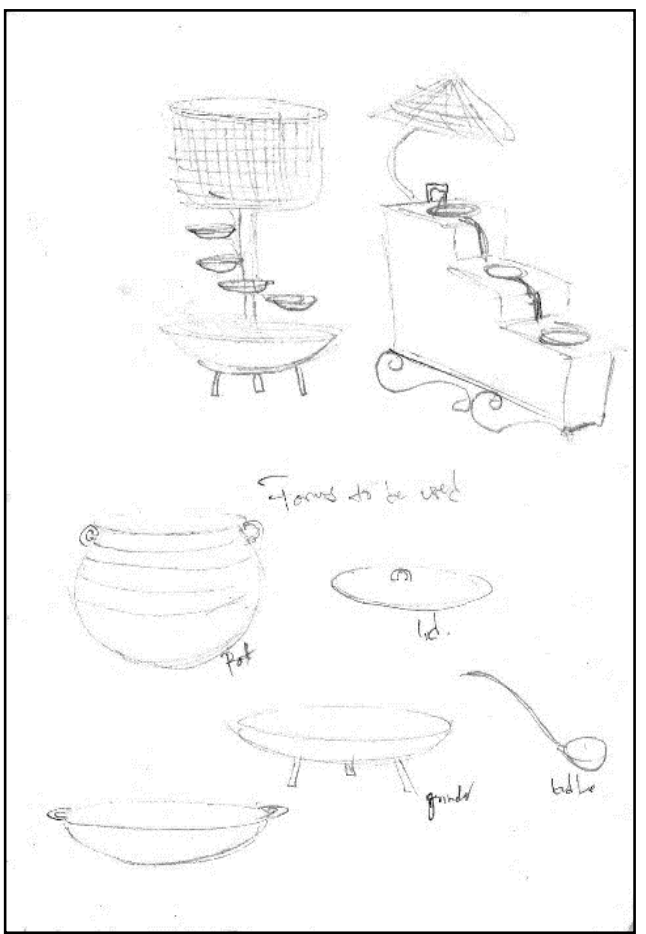

Fig 11:- Skeches of concepts cont'd

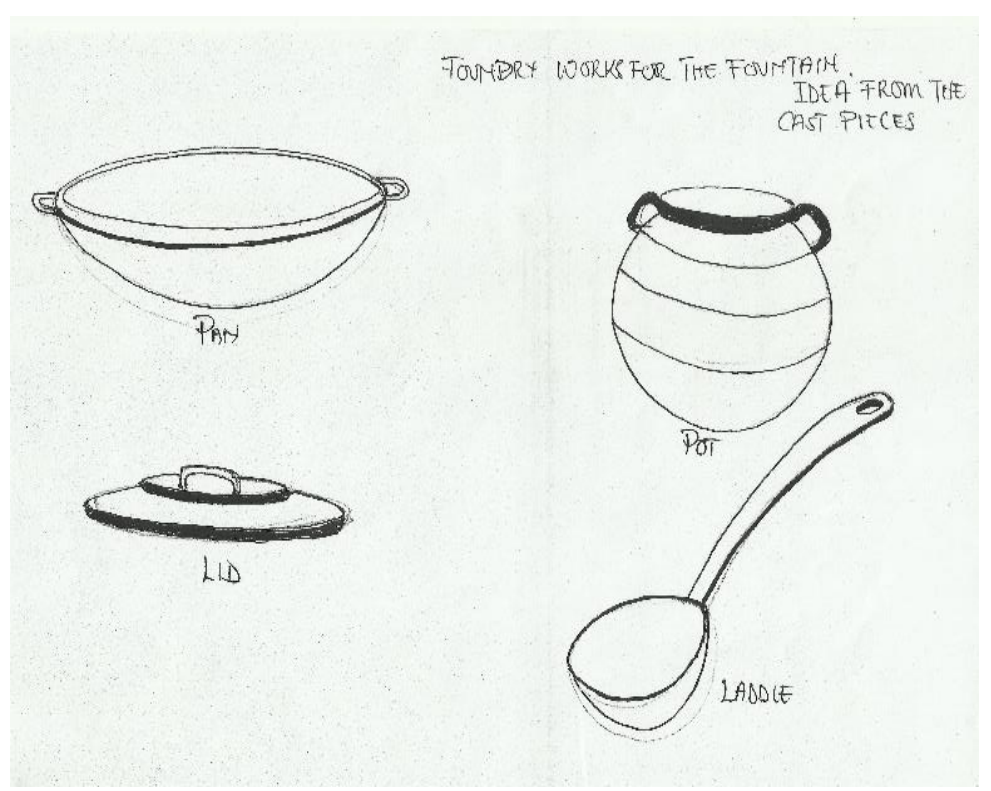

Fig 12:- Forms accesed.

The three selected sketches were subjected to matrix evaluation based on affordability, attractiveness, sustainability, strength, functionability, weight and size as the criteria for the evaluation. the different criterion were rated according to their level of importance in the integration. This is summarized in table 1. the chosen concept is presented in figure 13. the was analysed and rendered with three dimensional software as shown in figure 14. This was further explodes to take cognizance of all the parts as shown in 15 . 
ISSN No:-2456-2165

\begin{tabular}{|c|c|c|c|c|}
\hline CRITERIA & $\begin{array}{c}\text { IMPORTANCE } \\
\text { RATING }\end{array}$ & $\begin{array}{c}\text { CONCEPT } \\
\mathbf{9}\end{array}$ & $\begin{array}{c}\text { CONCEPT } \\
\mathbf{0}\end{array}$ & $\begin{array}{c}\text { CONCEPT } \\
\mathbf{\%}\end{array}$ \\
\hline AFFORDABILITY & $\mathbf{1 0 \%}$ & 8 & 8 & 5 \\
\hline ATTRACTIVENESS & $\mathbf{2 0 \%}$ & 15 & 19 & 19 \\
\hline SUSTAINABILITY & $\mathbf{7 \%}$ & 6 & 6 & 6 \\
\hline STRENGHT & $\mathbf{1 5 \%}$ & 6 & 10 & 11 \\
\hline FUNCTIONABILITY & $\mathbf{2 8 \%}$ & 23 & 27 & 5 \\
\hline WEIGHT (LIGHT) & $\mathbf{1 0 \%}$ & 6 & 5 & 6 \\
\hline SIZE (BULKY) & $\mathbf{1 0 \%}$ & 6 & 7 & 6 \\
\hline TOTAL & $\mathbf{1 0 0 \%}$ & $\mathbf{7 0 \%}$ & $\mathbf{8 2 \%}$ & $\mathbf{7 8 \%}$ \\
\hline
\end{tabular}

Table 1:- The matrix evaluation of the three selected sketches

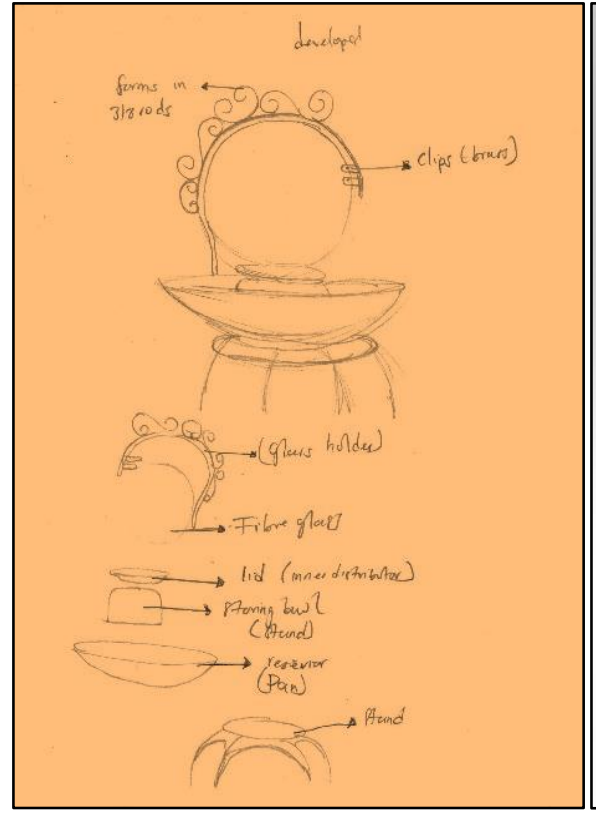

Fig 13:- Chosen Concept.

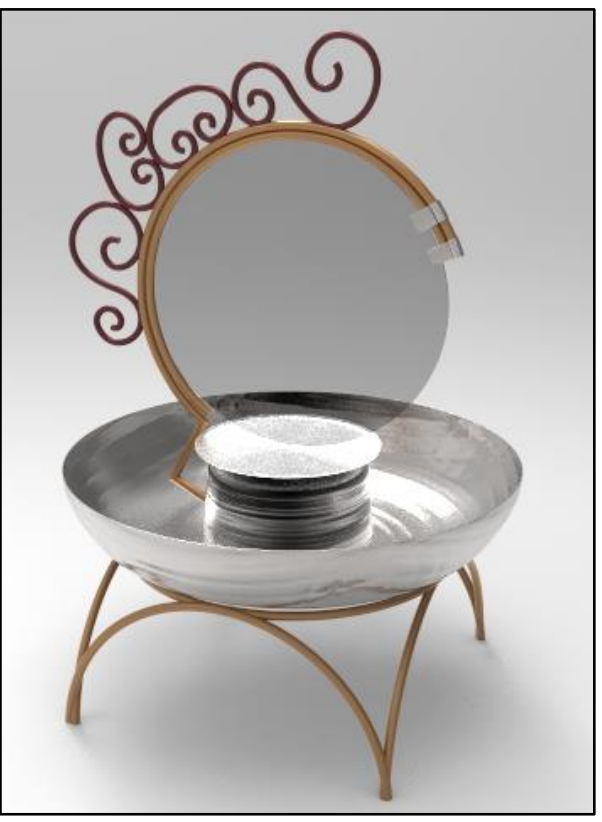

Fig 14:- Rhino rendition

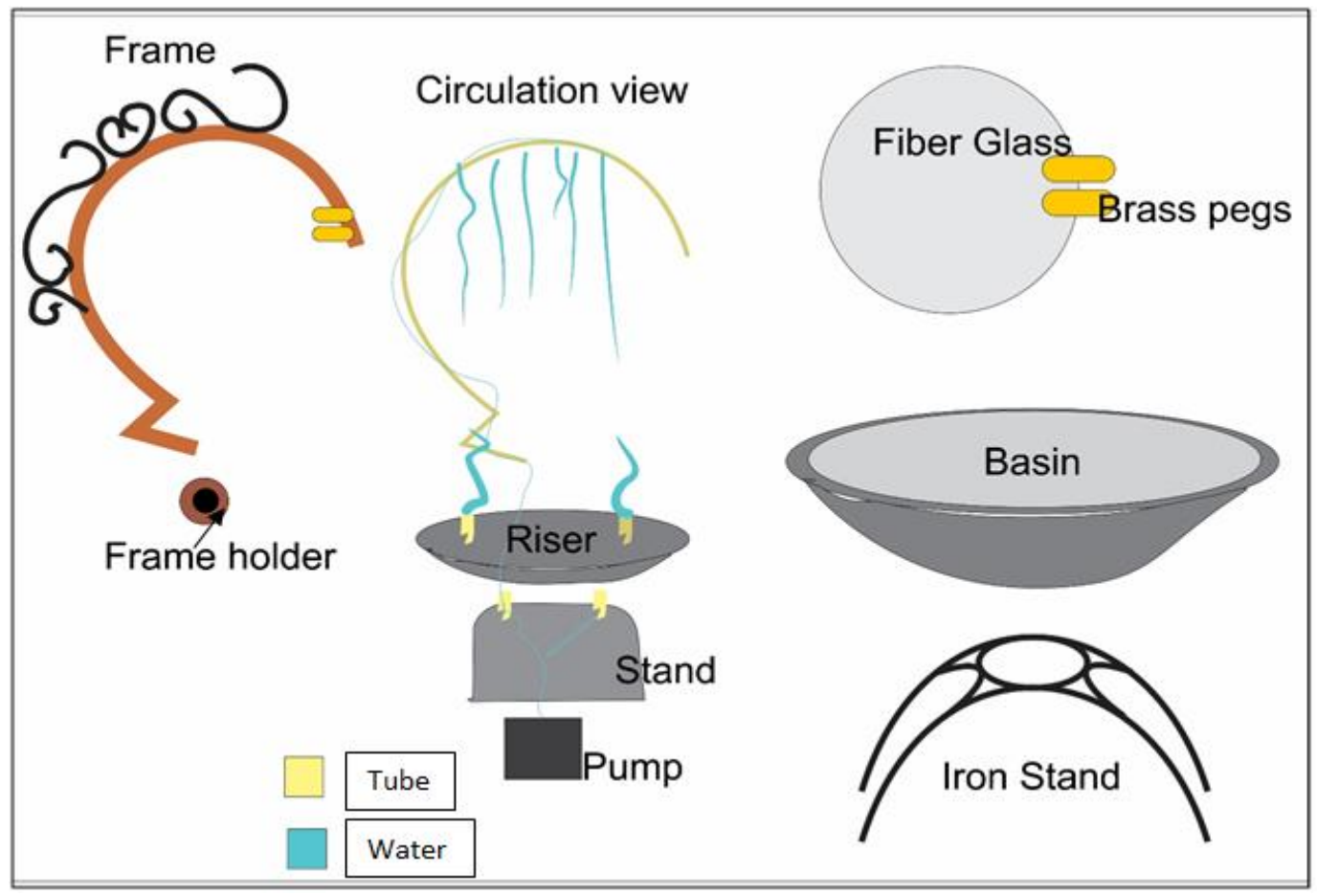

Fig 15:- An exploded view of the fiber glass fountain 
ISSN No:-2456-2165

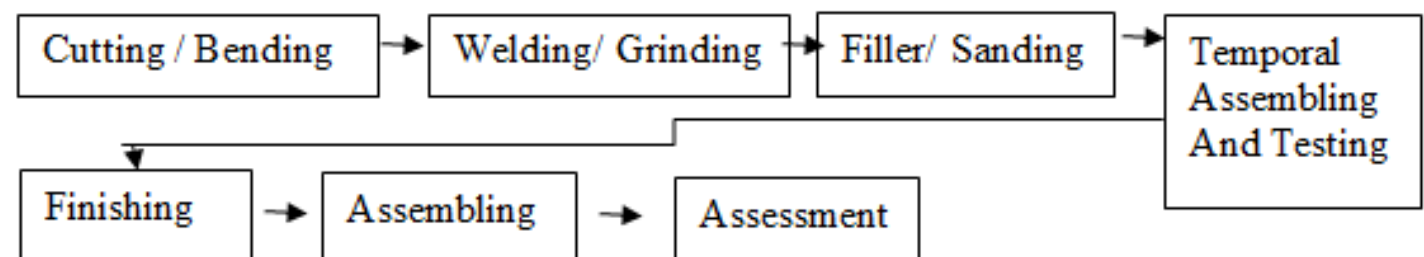

Fig 16:- The step approach employed in the executions of the selected concept

The working process employed tools such as Cross Cutter, Bellow, Welding Machine, Bending Stake, Spirit Level, Tape measure, Marker, Anvil, soldering iron and a try square. A 3/8 rod was forged according to the design. It was arranged and welded and trimmed to form frame and the stand for the basin. Red oxide and black matte paint were applied to the surfaces to preserve them.

A smaller tube was attached to the inner part of the frame rod by gluing (figure 17). Holes were punched using a soldering iron (figure 18). This was done such that the water walks on both surfaces of the fiber glass.

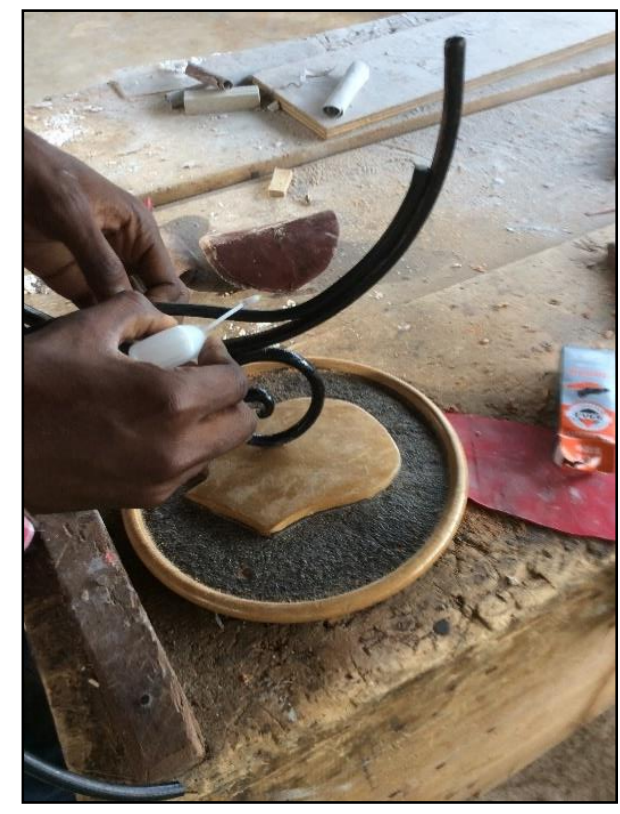

Fig 17:- Fixing the tubing system.

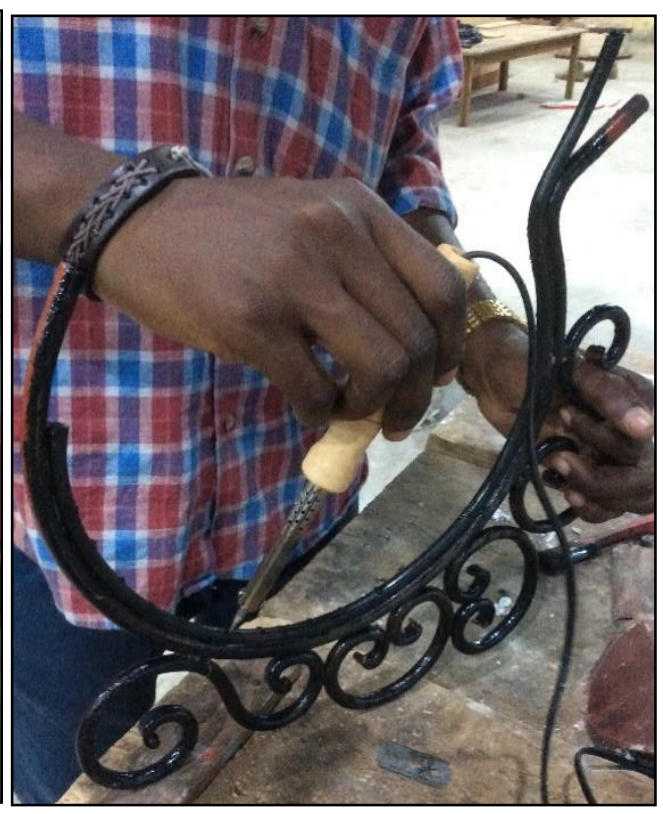

Fig 18:- Creating holes for water passage.

The aluminum utensils were prepared, namely: the pan, lid and storing bowl and was arranged according to the design. To join the iron to the storing bowl a washer was welded to the iron and holes were drilled (figure 19) and bolts passed through them (figure 20) that connect with corresponding holes created on the aluminum bowl. This mechanism was employed to stand the frame upright in the basin.

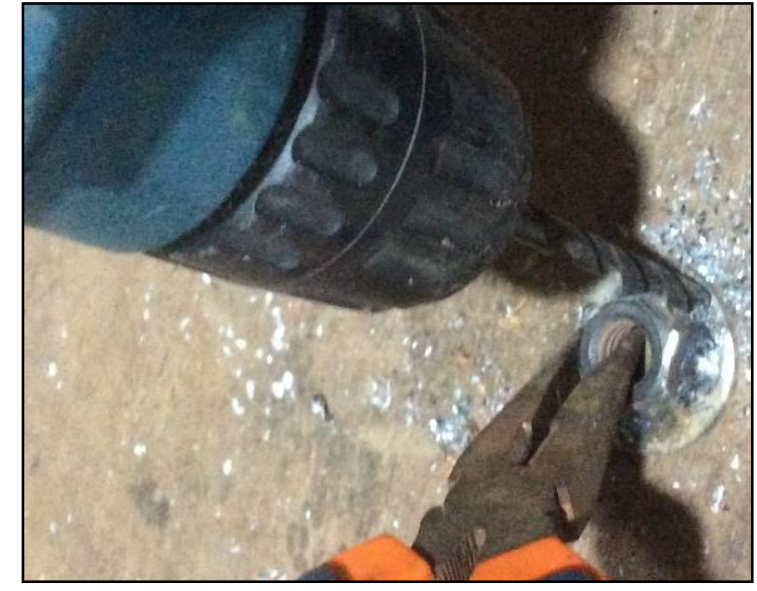

Fig 19:- Drilling the holding mechanism

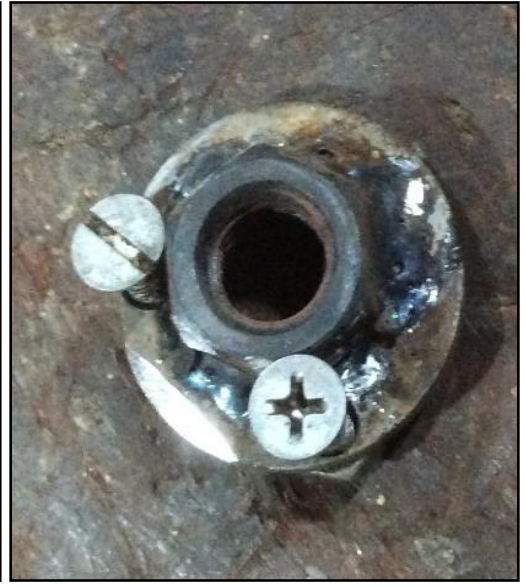

Fig 20:- Fixing the nut 


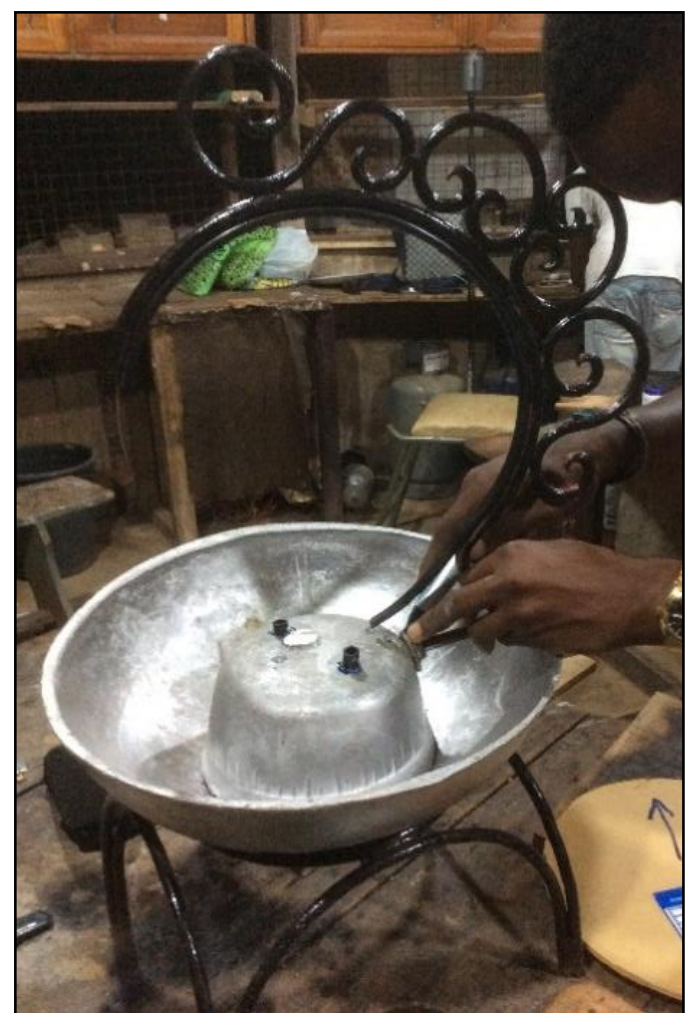

Fig 21:- connection of the frame to the basin

In cutting the fiber glass, the frame was used as a template to mark out the perimeter of the fiber glass (figure 19). This was then cut out using the scroll saw. The glass was finished well and corresponding hole were then drilled to facilitate the connection to the frame. Brass pegs were then made to hold the fiber glass and iron together (figure 23).

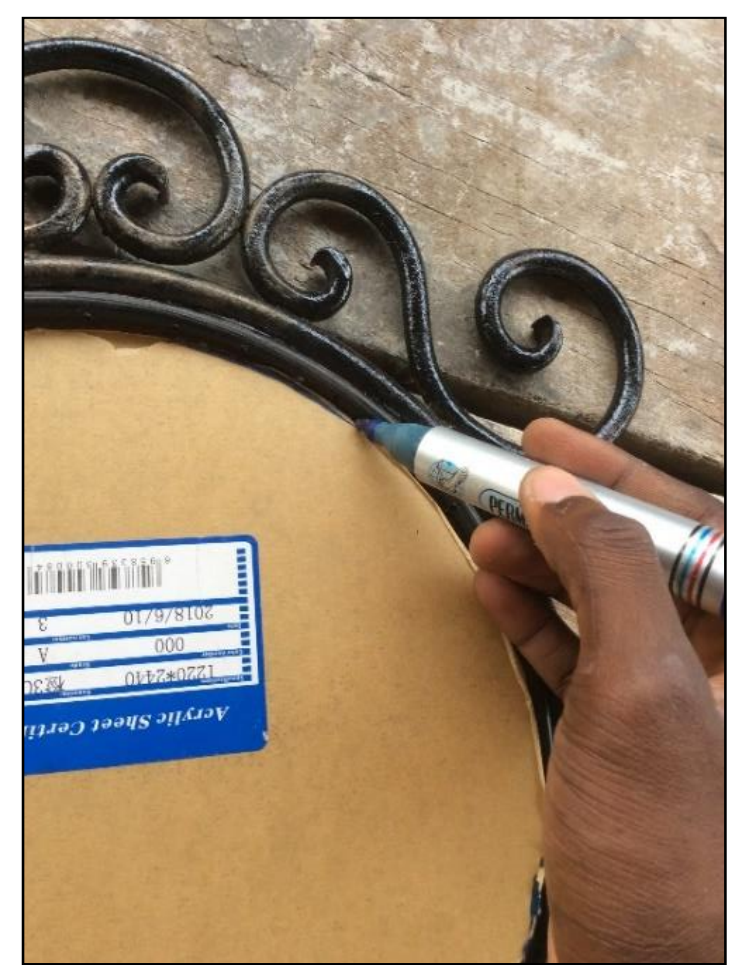

Fig 22:- Marking the fiber glass according to the frame. 


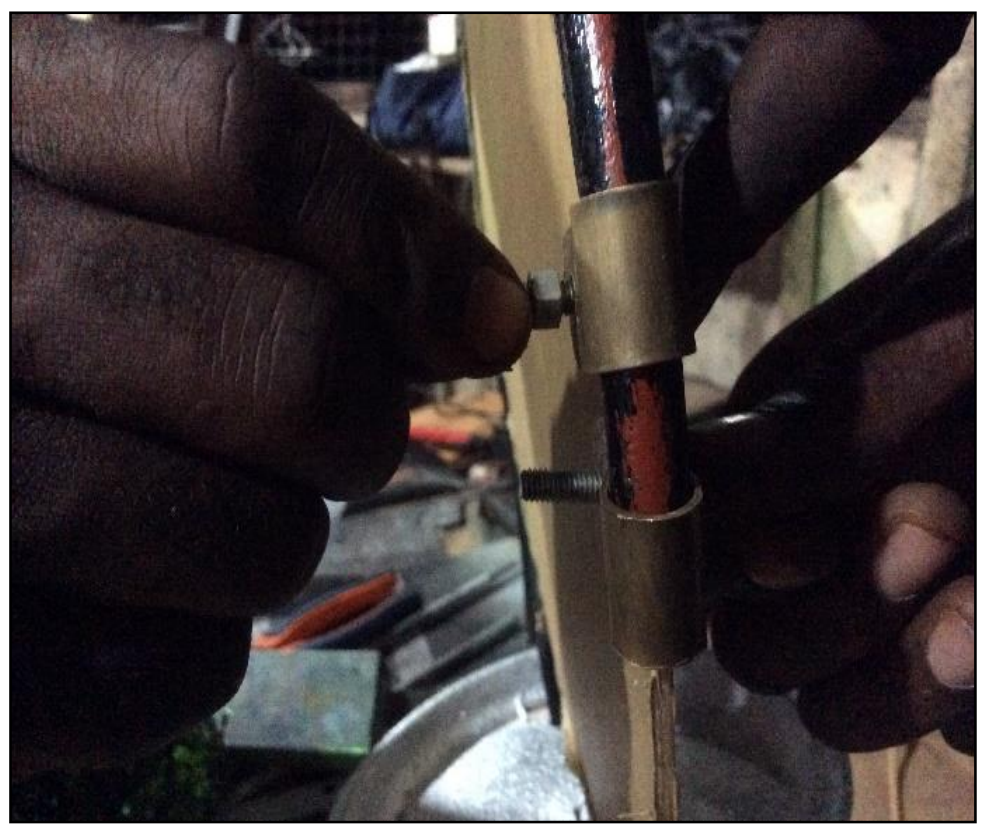

Fig 23:- connecting the frame and the fiber grass together using the brass pegs

Appropriated Holes were drilled into respective members according to the design to channel the conduits of the fountain from the basin to the outlet. These are shown in figures 24 and 25 respectively. This was followed by the assembling of the fountain which includes fixing of the pump. the final assembly is shown in figure 26. The fountain was then tested and after a successful test, it was then embellished with metallic paints to preserve it but also improve of the aesthetic looks as seen in figure 27.

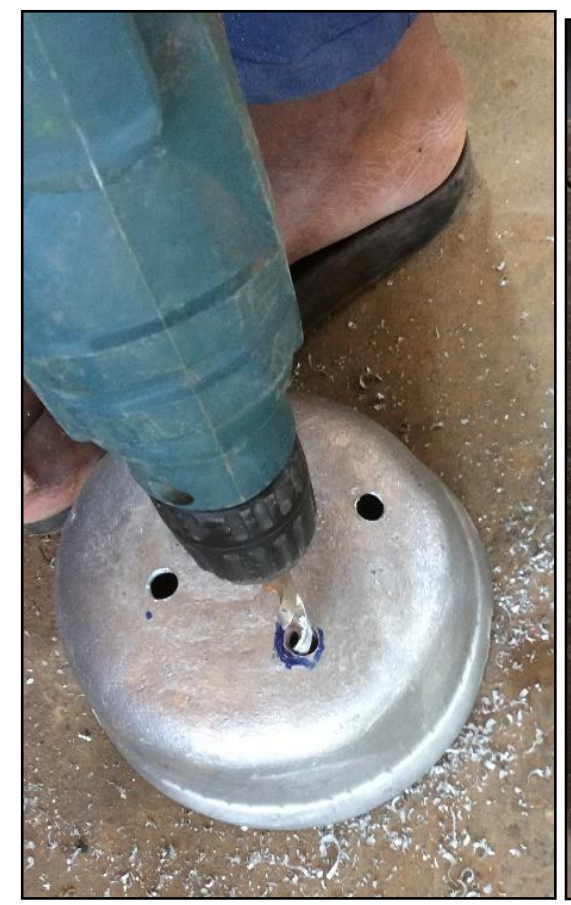

Fig 24:- drilling of conduit holes

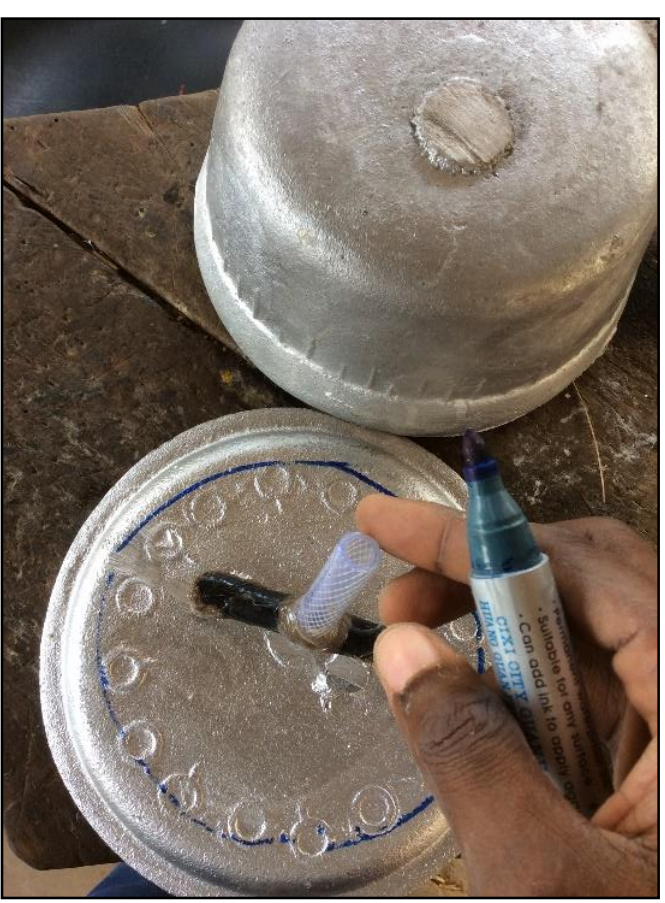

Fig 25:- connection of conduit 


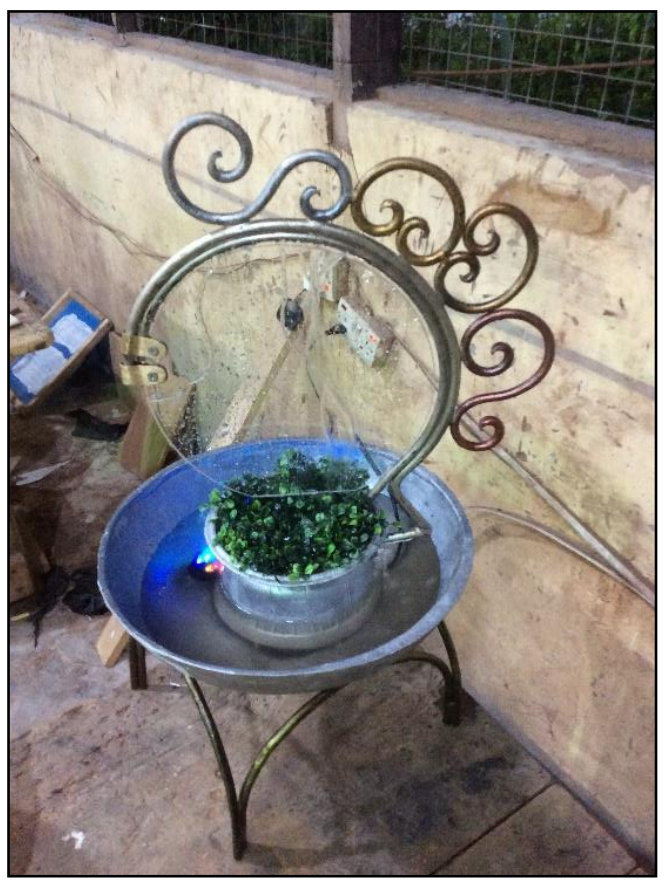

Fig 26:- Assembled fountain

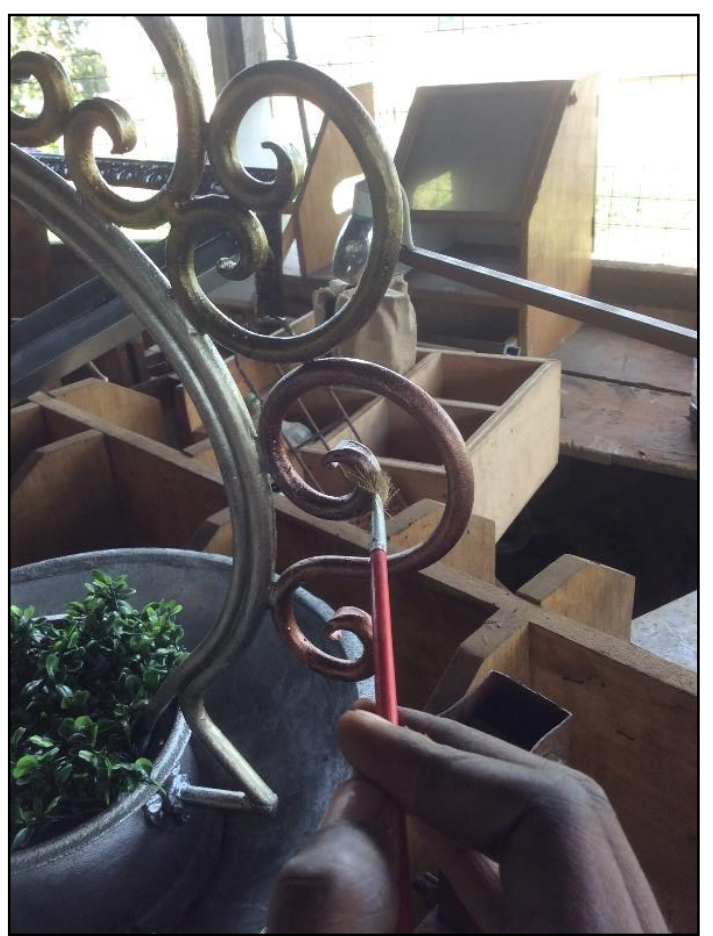

Fig 27:- Brush finishing was employed by using metallic paints.

\section{RESULTS AND DISCUSSIONS}

The result as seen in figure 28 is a portable fountain that allows water to rise gently and fall down the surface of the glass to create different movement and pattern one can keep watching. Despite that the others: the Pot, ladles, Spoons and Grinder were equally suitable and could have played the same role and function, the chosen three forms were much suitable for the design chosen as determined by the matrix evaluation. in this regard, different design descriptions and intention may give room to one utensil or the other to be used in a fountain. 


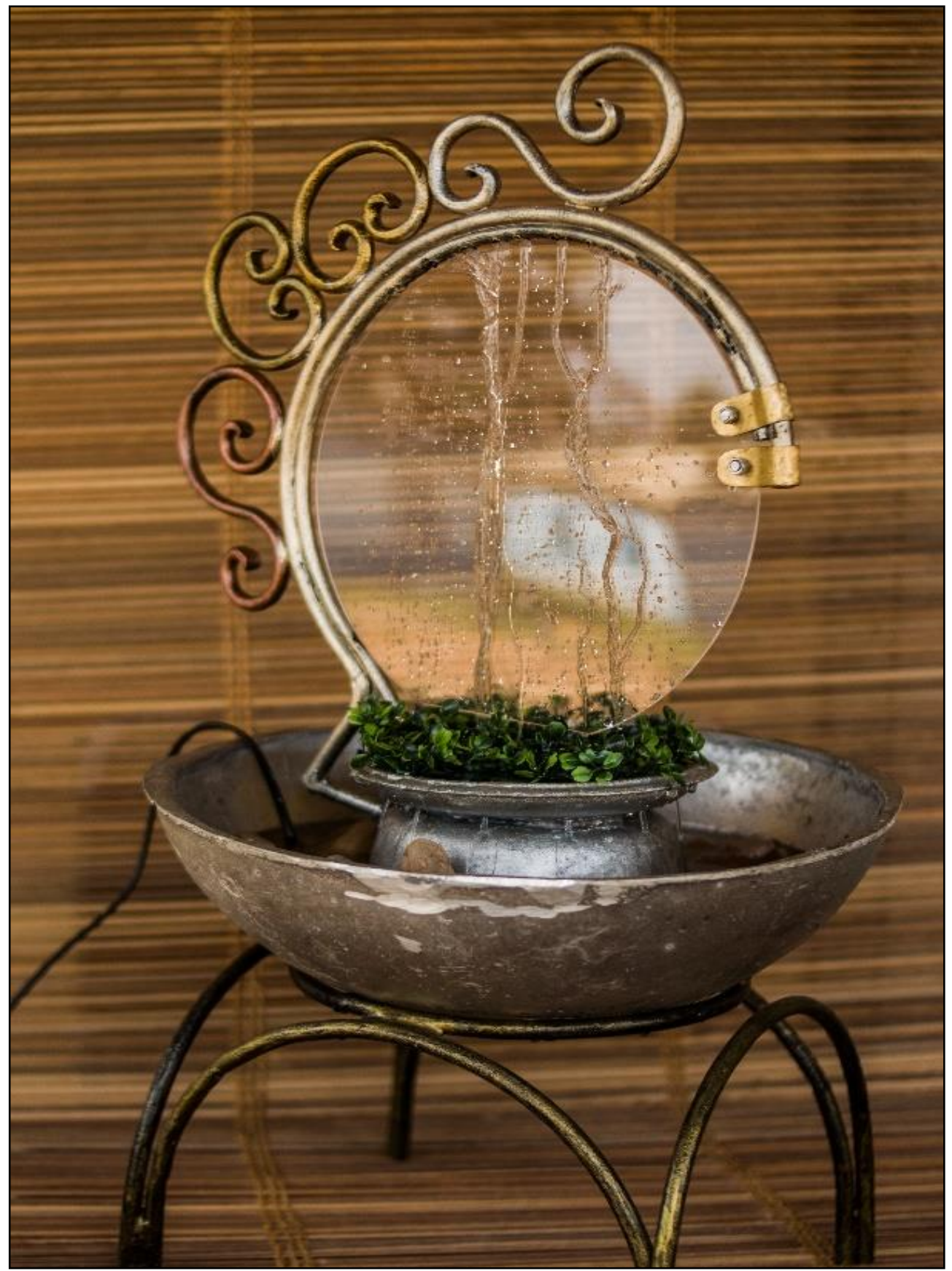

Fig 28:- The final piece.

The original colours of the utensils cannot be underestimated regarding the aesthetic appeal it can create when combined well with other materials and colours. in the construction cognsitance was take of the texture, colour, finishing and preservation, auxiliary materials, the type of pump and its features, joints and joining techniques and suitability in terms of use. This is summarized in figure 29. 


Texture; the smoothness
of the iron and the rough
surface of the utensil
created the beautiful
contrast seen on the
work.

Color; maintaining the silver color of the utensils made the other parts stand out. Painting of the auxiliary materials like the iron with metallic colors made the piece classy. Gold, bronze, copper and brass together creates the feel of class.

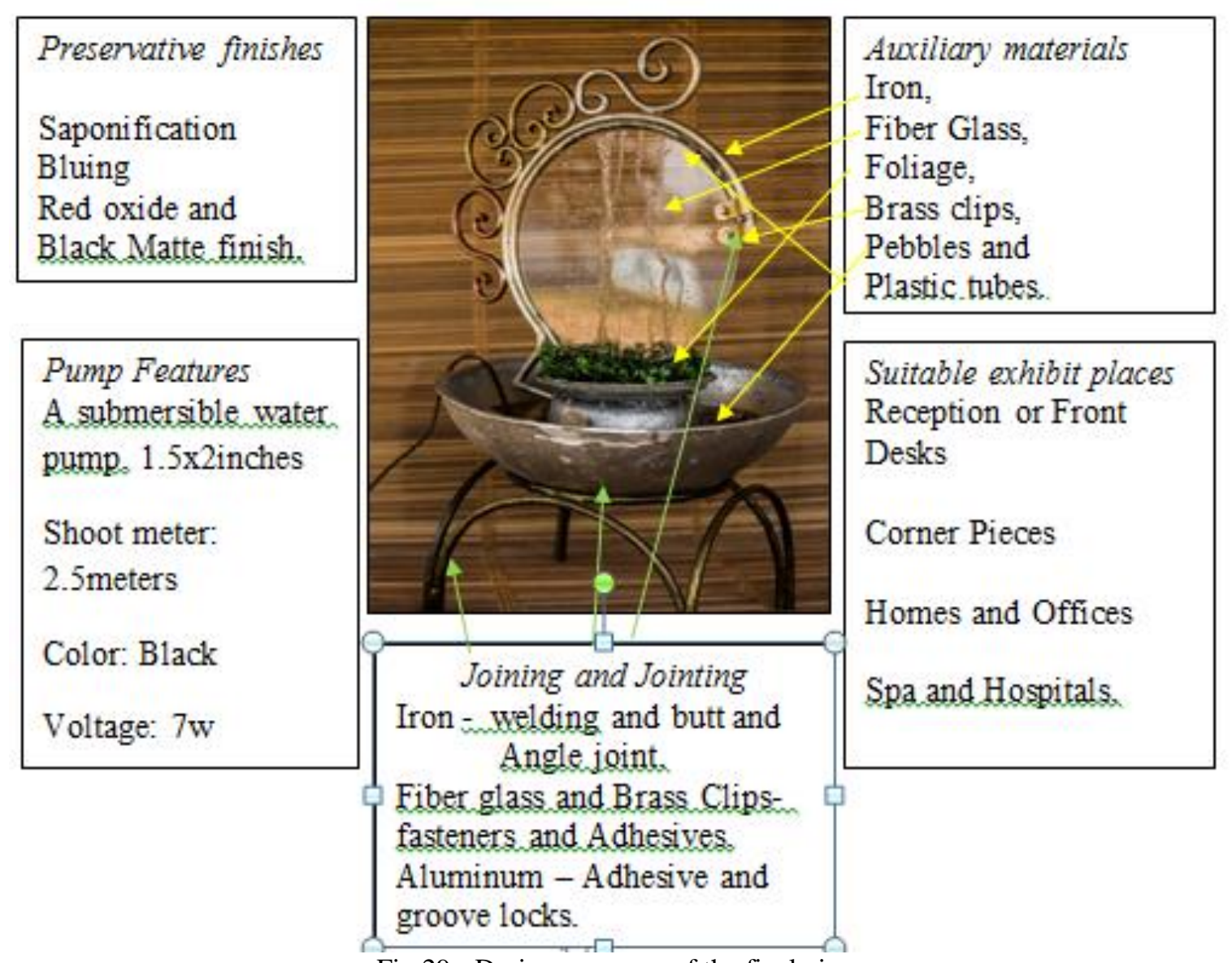

Fig 29:- Design summary of the final piece

Apart from the design above, the four parts that aids in a water fountain circulation which is the Basin, collector, distributors and stand or concealer are duly executed by the integration of the different utensils also seen in figures 30 and 31. The Basin which mostly would be referred to as the reservoir is where the activity called Pumping away is achieved. This is done with the help of a pump to help in recirculation. The half sphere nature of utensil forms like the Pan or Grinder is very suitable, because they come in wider openings and well depth to contain more water. The water is then pumped to its end point which is also similar to a basin but called a collector in this study. Apart from the grinder the collector also related well with the ladles and Pots depending on the size of fountain to be produced. Normally the pump is located in the basin of most of the design and for some exceptional ones the pump is hidden in a chamber which is the stand or concealer. This mostly makes use of utensil forms like the storing bowls, because they have some lengthy depths that can hold sizable pumps and their flat base also severs as a good stand for other component to be fixed on easily.

Channels of delivery or the distributors can sometimes make use of tubes as the final piece has employed. This connects from the pumps to the topmost part and delivers the water evenly on some ladles, spoon or preferably lids which are the ideal forms for fountain distributers aside tubes. figure 30 is s prototype of water fountains that involes other utensils that were not involved in the design of the recent concept. This involved the Pan, Grinders, Lids and Ladles. In this case the lid is the main distributor. another prototpe of a fountain is displayed in figure 31 that involves this time the grinder, ladles and storing bowls. 


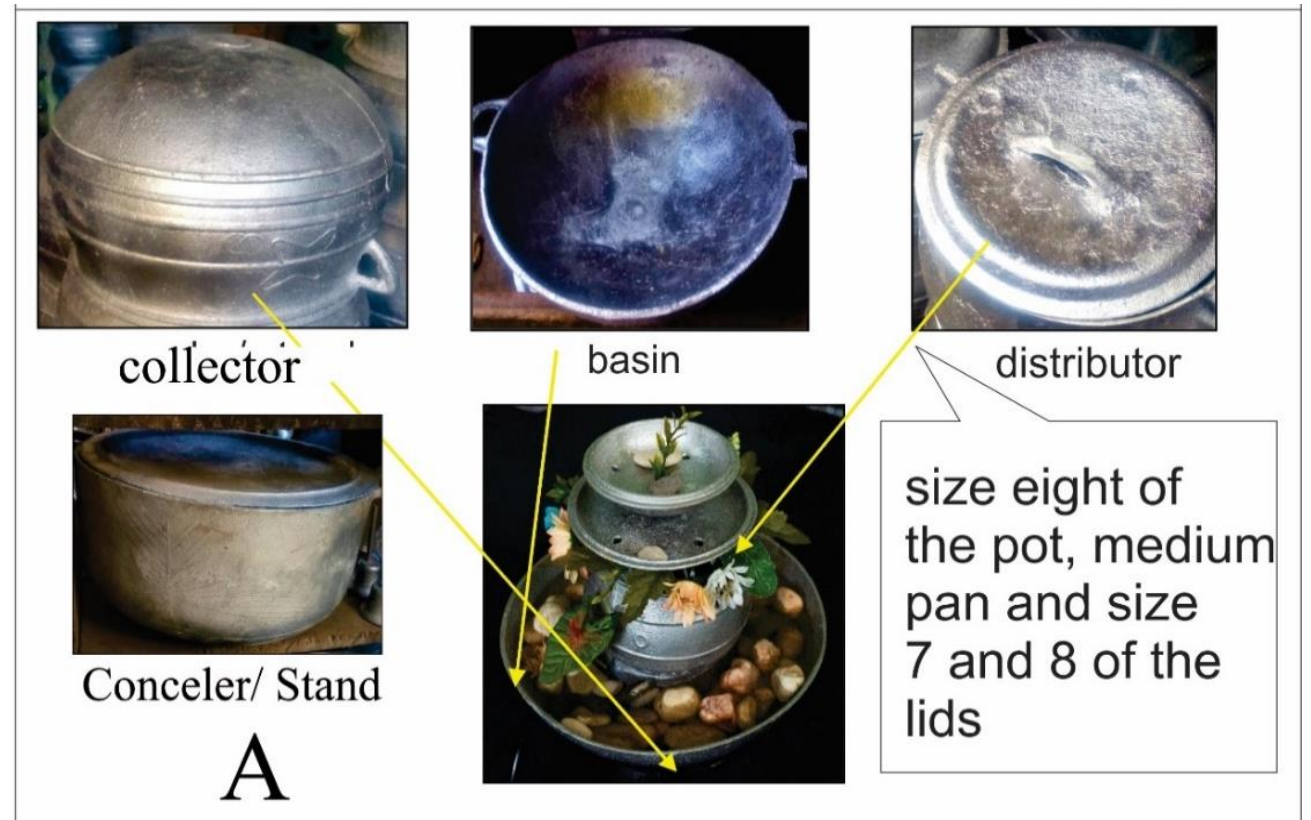

Fig 30:- A representation of the water fountain with the use of the pot (caldron), lids and pan

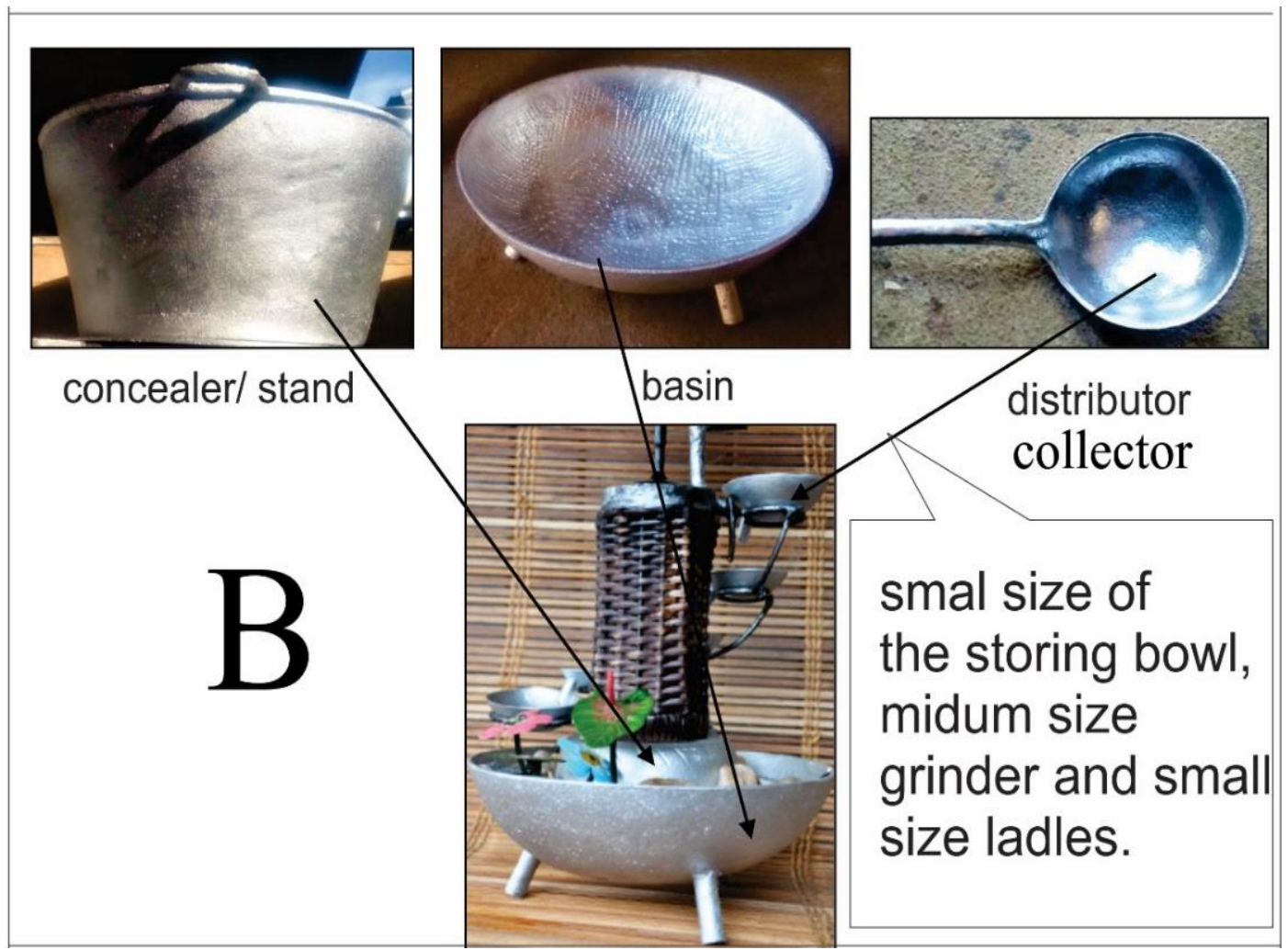

Fig 31:- A representation of the a fountain that involves the grinder, ladles and storing bowls.

\section{CONCLUSIONS}

The forms and functions of the Ghanaian Aluminum Cast utensils are good resource for fountains design and production. The study on the other hand has extensively identified some available forms that can serve useful purposes in fountain production. in all six forms were conclusive. These are in Figure 1: the metal pot (the caldron), Figure 3: The Storing bowl, Figure 5: The Baker or frier, Figure 6: The Grinder, Figure 7: The ladle and Figure 8: The Spoon. In terms of materials, the utensils have added to the fountain materials that are already in existence. It has on a larger scale proven its compatibility with other complementary materials like iron, rattan, wood etc. The challenges involved in using the utensils are manageable and within the technological provisions. the natural limitations of the utensils posed as challenges can be considered artistically as a new style and not a blemish that can degrade a resulting fountain. 


\section{RECOMMENDATIONS}

The study recommends to fountain producers to diversify the materials they use in fountain production with local materials and specially recommends aluminium cast utensils as an option. It's also to recommended artists who are interested in using the utensil for fountains to explore into the other different types of fountains that were not stated in this study. Besides, they should liaise with the local founders to produced forms that are friendlier to their designs apart from the traditional utensils on the market.

The study recommends to the Metal section of the Department of Integrated Rural art and Industry of the Kwame Nkrumah University of Science and Technology to continue to encourage their student to keep exploring the utensils and the local industry with a focused attention. In this regard, students should be allowed to express themselves with these utensils among other local materials in artifact production. This will lead to the discovery of new avenues of subjecting these local materials into a profitable use for economic advancement.

\section{REFERENCES}

[1]. Beyond the Veranda, (2014). beyondtheverandal menu/ types of garden funtains. [Online] Available at: https://www.beyondtheveranda.com/types-of-gardenfountains/ [Accessed 3 feburary 2019].

[2]. Cotton, L. (2004-2015). Laminar flow waer fountain. Retrieved december 2, 2015, from Makezine.com: makezine.com/projects/make-32/laminar-flow-waterfountain/

[3]. Ganiho, M. A. (2015, october 15). (H. I. Timothy, Interviewer)

[4]. Hannah, M. (2015, october 15). (A. Benjamin, Interviewer)

[5]. Jessica Kolifrath, D. M. (n.d.). SFGATE.com. Retrieved december 2, 2015, from Sfgate.com: homeguides.sfgate.com/recirculating-water-fountainoperate-89593.html 